\title{
Erratum to: Production of Reactive Oxygen Species and Application for NOx Control
}

\author{
Mindi Bai · Baiyu Leng $\cdot$ Shoulei Mao
}

Published online: 6 August 2014

(C) Springer Science+Business Media New York 2014

\section{Erratum to: Plasma Chem Plasma Process (2014) 34:83-92 DOI:10.1007/s11090-013-9493-1}

In the original publication of the article, a co-author Dr. Shoulei Mao's name has been erroneously submitted and published. The error in the author's name is now corrected with this erratum.

The online version of the original article can be found under doi:10.1007/s11090-013-9493-1.

M. Bai $(\bowtie) \cdot$ S. Mao

Department of Physics, Dalian Maritime University, Dalian 116026, China e-mail: mindibai@163.com

B. Leng

School of Light Industry and Chemical Engineering, Dalian Polytechnic University, Dalian 116034, China 